\title{
COMPARISON OF PHYSICAL CONDITION PROFILES OF ELITE AND NON-ELITE YOUTH FOOTBALL PLAYERS
}

\author{
Ahmad Nasrulloh ${ }^{1}$, Yudik Prasetyo $^{1}$, Sumaryanto $^{1}$, Sulistiyono $^{1}$, Rina Yuniana ${ }^{1}$ \\ ${ }^{1}$ Fakultas Ilmu Keolahragaan, Universitas Negeri Yogyakarta Colombo No. 1, Karangmalang Depok, Sleman, \\ Yogyakarta, Indonesia \\ Email:*ahmadnasrulloh@uny.ac.id, yudik@uny.ac.id,sumaryanto@uny.ac.id, sulistiyono@uny.ac.id, \\ rinayuniana@uny.ac.id
}

\begin{abstract}
Performance of a football player in a competitive match is influenced by good physical condition in training, competing, or in everyday life. Comprehensive ability is the hope of all football coaches. The study was conducted to determine how the comparison of the physical condition profile of youth football players in the elite and non-elite categories at the provincial level football federation, especially in SSB in the Special Region of Yogyakarta. The research method used in this research is descriptive quantitative. The subjects of this study were students or soccer athletes in elite and nonelite youth football players. The population that the researchers determined was elite and non-elite youth football players at football schools or football clubs in the DIY Province. The sampling technique was carried out by means of purposive random sampling. The instrument in this study used the MFT / Yoyo Intermittent Test, Vertical Jump Test, 30 meter Sprint Test, Illinois Test, and Sit and Reach. Based on the results of the study, it shows that the body mass index component with an average of 19.53 elite players and 19.78 non-elite players. Flexibility, elite players 34.40 and non-elite players 31.14. The leg power of elite players is 45.52 and for non-elite players is 45.28. The speed component is 4.48 for elite and non-elite players, 4.95. For coordination, the elite players are 53.04 and the nonelite players are 51.20. The agility of the elite players is 18.68 and the non-elite players are 18.99. Meanwhile, the aerobic endurance for elite players was 39.85 and non-elite players were 37.97. So it can be concluded that the physical condition of soccer players which includes body mass index, flexibility, leg power, speed, coordination, agility and endurance, elite players show better results compared to non-elite players.
\end{abstract}

Keywords: physical condition, football players, elite, non-elite

\section{PERBANDINGAN PROFIL KONDISI FISIK PEMAIN SEPAKBOLA REMAJA ELITE DAN NON-ELITE}

\begin{abstract}
Abstrak
Kinerja (Performance) pemain sepakbola dalam suatu pertandingan kompetisi dipengaruhi oleh kondisi fisik yang baik dalam latihan, bertanding, atau di dalam kehidupan sehari-hari. Kemampuan yang komprehensif merupakan harapan seluruh pelatih sepakbola. Penelitian dilakukan untuk mengetahui bagaimana perbandingan profil kondisi fisik pemain sepakbola remaja pada kategori elit dan non-elit pada federasi sepakbola tingkat provinsi khususnya di SSB di Daerah Istimewa Yogyakarta. Metode penelitian yang digunakan dalam penelitian ini adalah deskriptif kuantitatif. Subjek penelitian ini adalah siswa atau atlet sepakbola pada pemain sepakbola remaja elite dan nonelite. Populasi yang peneliti tetapkan adalah pada pemain sepakbola remaja elite dan non-elite pada sekolah sepakbola atau klub sepakbola di wilayah Provinsi DIY. Teknik penetapan sampel dilakukan dengan cara purposive random sampling. Instrumen dalam penelitian ini menggunakan MFT/Yoyo Intermittent Test, Vertical Jump Test, 30-meter Sprint Test, Illinois Test, akan Sit And Reach. Berdasarkan hasil penelitian bahwa menunjukkan bahwa komponen indeks massa tubuh dengan rerata pemain elite sebesar 19,53 dan non elite sebesar 19,78. Fleksibilitas, pemain elite 34,40 dan non elite sebesar 31,14. Power tungkai pemain elite sebesar 45,52 dan pada pemain non elite 45,28. Komponen kecepatan yaitu 4,48 pada pemain elite dan non elite 4,95. Koordinasi, pemain elite sebesar 53,04 dan
\end{abstract}


non elite 51,20. Kelincahan pemain elite sebesar 18,68 dan pada pemain non elite 18,99. Sedangkan daya tahan aerobik pemain elite sebesar 39,85 dan pemain non elite sebesar 37,97. Sehingga dapat disimpulkan bahwa kondisi fisik pemain sepak bola yang meliputi indeks massa tubuh, fleksibilitas, power tungkai, kecepatan, koordinasi, kelincahan dan daya tahan, pemain elite menunjukkan hasil yang lebih baik dibandingkan dengan pemain non-elite.

Kata Kunci: kondisi fisik, pemain sepakbola, elite, non-elite

\section{PENDAHULUAN}

Sepakbola merupakan olahraga permainan yang dilakukan secara beregu, setiap regu terdiri dari sebelas pemain, dimana salah satu pemain sebagai penjaga gawang, dan dalam permainan seluruh pemain menggunakan kaki kecuali penjaga gawang yang boleh menggunakan tangan di daerah hukumannya (Sucipto, dkk, 2000). Beberapa peraturan yang yang telah ditetapkan yaitu jumlah pemain, ukuran gawang, istilah off side, (FIFA, Federation International of Football Association, 2018). Kompetisi sepakbola antar Negara menetapkan peraturan umum dan khusus yang berbeda dengan kompetisi sepakbola antar klub. Kompetisi sepakbola kelompok umur 19 tahun menetapkan peraturan permainan, pertandingan umum dan khusus yang berbeda dengan kompetisi sepakbola kelompok umur 17, 15 atau 13 tahun tetapi hakekat dari permainan sepakbola tidak hilang dalam berbagai model kompetisi sepakbola yang berbeda. Modifikasi peraturan permainan diperbolehkan sesuai dengan model kompetisi yang diselenggarakan.

Pembinaan pemain muda berjenjang, terprogram, terus-menerus sejak usia 7-19 tahun melalui berbagai organisasi seperti sekolah formal, sekolah sepakbola, pusat pengembangan bakat, Akademi sepakbola yang menyebabkan klub-klub di Eropa dan tim nasional negaranegara Eropa seolah tidak pernah kehabisan pemain hebat. Pembinaan dilakukan berjenjang dimulai dari pengembangan gerak dasar, pengembangan bakat, pengembangan anak-anak berbakat istimewa, sampai pada pembinaan pemain elite, dimulai dari usia 7-11 tahun, 12-14 tahun, 15-19 tahun, dan 19-21 tahun (www.dfb.com).

PSSI (Persatuan Sepakbola Seluruh Indonesia) sebagai lembaga formal yang bertugas membina dan mengembangkan prestasi sepakbola nasional dalam upayanya membangun dan mengembangkan prestasi tim nasional baik senior maupun yunior telah melakukan berbagai upaya diantarannya menyelenggarakan kompetisi antar sekolah sepakbola, akademi sepakbola, klub sepakbola yang berjenjang pada seluruh kelompok umur dari usia 13, 15. 17, 19 tahun dan usia dewasa atau senior. Penyelengaraan berbagai kursus pelatih, wasit, dan berbagai seminar untuk meningkatkan kompetensi sumber daya manusia pelaku pembinaan sepakbola Indonesia. Semua upaya yang dilakukan berujung pada peningkatan kualitas pemain sepakbola sebagai penentu utama kinerja sebuah tim sepakbola selain pelatih.

PSSI menetapkan dan mengatur bahwa pelaku atau organisasi yang bertugas mencetak calon pemain sepakbola adalah sekolah sepakbola (SSB), akademi atau Pusdiklat (Pusat Pendidkan dan Latihan) dan klub sepakbola. Pada sekolah sepakbola melakukan proses pembinaan pada pemain muda usia 7-15 tahun, sedangkan akademi sepakbola atau klub sepakbola melakukan pembinaan pada pemain berusia 16 tahun sampai dengan 19 tahun. Klub sepakbola merupakan wadah pembinaan pemain sepakbola senior atau usia 19 tahun lebih. Struktur pembinaan dalam olahraga permainan sepakbola dari mulai usia muda 7-15 tahun, 16-19 tahun, dan usia dewasa dapat dilihat pada gambar 1 berikut ini. 

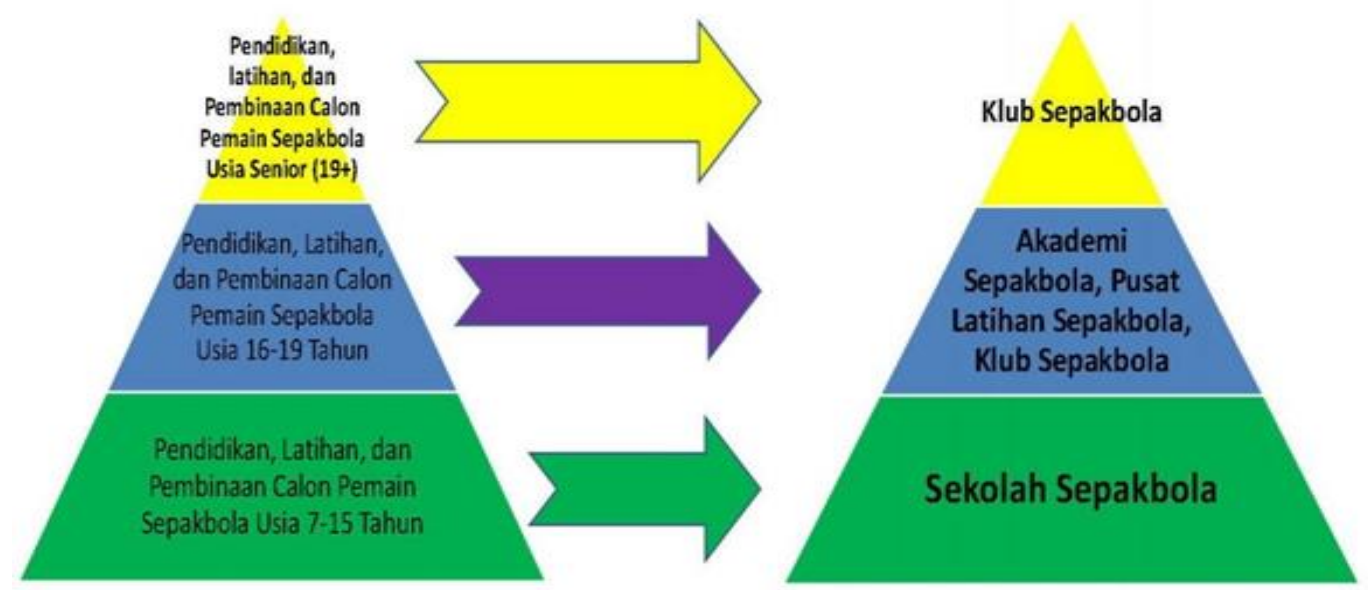

Gambar 1. Jenjang dan Pelaku Pembinaan Cabang Olahraga Sepakbola di Indonesia

Sistem pembinaan sepakbola yang dikembangkan oleh PSSI telah berjalan walaupun prestasi yang diharapkan belum tercapai. Sekolah adalah suatu lembaga yang memberikan layanan berupa pendidikan, proses belajar dan mengajar. Istilah sekolah merupakan istilah yang lazim digunakan untuk suatu lembaga yang memberikan layanan pendidikan pada jenjang pendidikan dasar dan menengah. Sedangkan untuk jenjang pendidikan tinggi dapat dilaksanakan oleh perguruan tinggi, sekolah tinggi, universitas, institut, atau politeknik (PP No 17 Tahun 2010).

Sekolah Sepakbola (SSB) adalah lembaga pendidikan informal yang berfungsi memberikan layanan pengetahuan, keterampilan, dan sikap dalam bermain sepakbola dengan usia maksimal 12 tahun, akademi sepakbola adalah Lembaga pendidikan in formal yang berfungsi memberikan layanan pengetahuan, keterampilan, dan sikap dalam bermain sepakbola dengan usia maksimal 13-17 tahun, sedangkan Klub Sepakbola adalah Lembaga atau organisasi berfungsi memberikan layanan pengetahuan, keterampilan, dan sikap dalam bermain sepakbola kepada pemain 18+, (Askab PSSI Kabupaten Sleman, 2018).

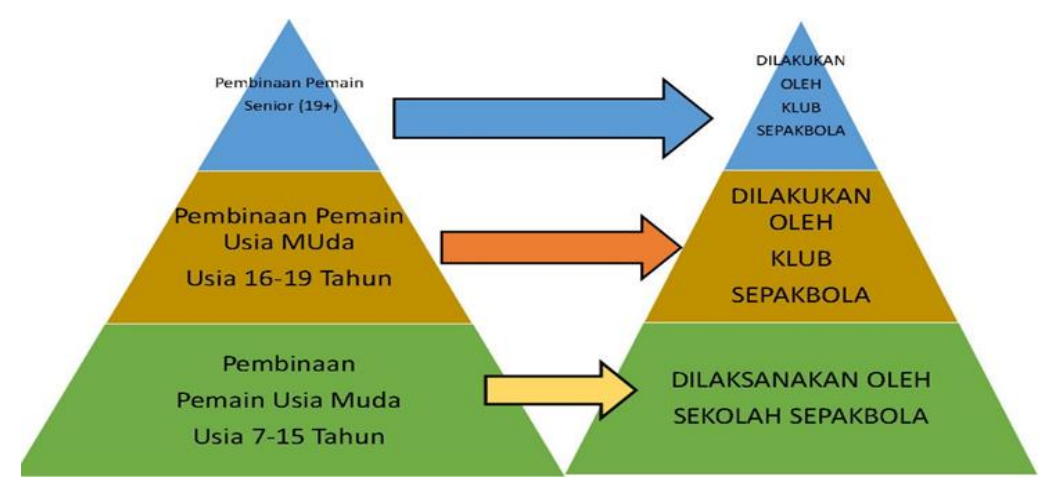

Gambar 2. Struktur Pembinaan Sepakbola di Indonesia

Layanan pelatihan pada siswa antara suatu SSB dengan SSB lainnya masih berbedabeda tetapi pada dasarnya pengelompokan siswa didasarkan pada kelompok umur siswa. SSB umumnya memberikan layanan latihan dengan prinsip satu (1) pelatih menangani 20-25 pemain berdasarkan usia. Pembagian siswa bedasarkan usia yaitu sebagai berikut kelompok umur 8, 10, 12, 14, dan maksimal 16 tahun. Fase usia 15 atau 16 tahun merupakan usia dimana layanan latihan dapat dberikan oleh SSB atau akademi sepakbola atau klub sepakbola sampai dengan usia 18 tahun. Program latihan pada siswa SSB difokuskan pada pengembangan keterampilan teknik, taktik, fisik dan mental. 
Jumlah SSB yang sangat besar di Indonesia belum berkorelasi positif dengan prestasi tim nasional sepakbola Indonesia dan klub-klub sepakbola Indonesia ditingkat Asia. Keprihatinan terhadap prestasi semakin diperparah oleh kondisi fisik pemain sepakbola didalam lapangan ketika bertanding maupun diluar lapangan atau dalam kehidupan seharihari. Kualitas pemain pada jenjang senior (usia dewasa) merupakan hasil dari pembinaan ketika pemain berada pada usia remaja (junior), dan kualitas pemain pada usia remaja (junior) merupakan hasil dari pembinaan ketika para pemain tersebut berada pada usia anak-anak. Evaluasi terhadap seluruh proses dan tahapan pembinaan seharusnya dilakukan untuk memproleh gambaran sebenarnya dimana letak kelemahan dan kekurangan pada proses pembinaan sepakbola di Indonesia.

Keterampilan fisik atau dalam beberapa referensi lebih sering disebut physical conditioning, physical ability, physical fitness atau sering disebut dalam bahasa Indonesia yaitu kondisi fisik. Kondisi fisik dalam bahasa yang lain disebut juga kebugaran jasmani yang terdiri dari kebugaran jasmani yang berhubungan dengan kesehatan dan kebugaran jasmani yang berhubungan dengan keterampilan. Berikut komponen kodisi fisik yang paling dibutuhkan oleh cabang sepakbola: daya tahan aerobik, power otot, kecepatan berlari, kelincahan (Straton, Gareth, Thomas Reily, 2004).

Tabel 1. Karakter Fisik Pemain Sepakbola Elite Menurut FIFA

\begin{tabular}{ll}
\hline Tinggi Badan & $181 \mathrm{~cm}$ \\
\hline Berat Badan & $74 \mathrm{~kg}$ \\
\hline Daya Tahan Aerobik (VO2 Maks) & $60-65 \mathrm{cc}$ \\
\hline Kecepatan Sprint $10 \mathrm{~m}$ & $1 " 78 \mathrm{sec}$ \\
\hline Kecepatan Sprint $20 \mathrm{~m}$ & $2 " 89 \mathrm{sec}$ \\
\hline Kecepatan Sprint $60 \mathrm{~m}$ & $733 \mathrm{sec}$ \\
\hline Daya ledak otot tungkai, Melompat keatas (Vertical Jump) & $63 \mathrm{~cm}$ \\
\hline Cepat dalam bergerak dan berlari & \\
\hline Dinamis & \\
\hline Keterampilan Teknik Tinggi & \\
\hline Daya Ledak Otot & \\
\hline Kemampuan untuk pulih lebih cepat & \\
\hline Pemahaman terhadap Taktik & \\
\hline Kekuatan Mental dan Kontrol diri & \\
\hline
\end{tabular}

Sumber: fifa.com

Komponen fisik berdasarkan Tabel 1 diatas yang perlu mendapatkan perhatian adalah daya tahan aerobik, kecepatan berlari, dan daya ledak otot tungkai. Daya tahan aerobik, kecepatan berlari, dan daya ledak otot tungkai merupakan tiga komponen utama yang secara terukur harus dimiliki atau dicapai jika sebuah tim berkeinginan berada dalam level elite dunia. Beberapa uraian diatas menunjukkan bahwa kondisi fisik merupakan faktor penting yang harus dipersiapkan oleh pelatih sepakbola jika tim yang dipimpinnnya ingin prestasi optimal (menjadi juara) dalam sebuah kompetisi. (Bompa \& Buzzichelli, 2015) menyatakan kondisi fisik merupakan kemampuan dasar yang harus dibangun dan dikembangkan pada atlet atau olahragawan termasuk pada cabang sepakbola. 
Ong dan Ong, (2009) menemukan bahwa profil kondisi fisik pemain sepakbola muda elite di Eropa, Afrika, dan Asia memiliki rerata daya tahan aerobic sebesar 60,25. Sedangkan atlit muda Indonesia memiliki rerata daya tahan aerobik sebesar 48,00 (Sulistiyono, 2015). Sehingga dapat disimpulkan bahwa kualitas pembinaan pemain usia muda di Indonesia secara umum perlu mendapatkan evaluasi dan perbaikan karena dari indikator daya tahan aerobik pemain sepakbola usia muda Indonesia jauh tertinggal dari para pemain muda elit di Eropa, atau Afrika, bahkan Asia. Oleh karena itu masih perlu kerja keras untuk meningkatkan kemampuan kondisi fisik atlit sepakbola di Indonesia, dimana kondisi fisik merupakan salah satu bagian dari indikator keterampilan bermain sepakbola.

Kondisi fisik adalah dasar atau pondasi yang harus dibuat dengan kokoh agar faktor teknik dan taktik dapat dilakukan sesuai dengan kebutuhan. Seorang atlet atau tim sepakbola yang tidak memiliki kemampuan kondisi fisik yang baik sebaiknya tidak perlu berharap pada target atau sasaran untuk menjadi juara. Menendang bola tidak hanya dilakukan dengan keterampilan teknik yang benar tetapi dituntut hasil tendangan yang keras (cepat lajuanya). Kecepatan berlari yang sangat cepat dari seorang pemain sepakbola tidak hanya dilakukan sekali atau dua kali tetapi sprint harus dilakukan berulang-ulang sesuai kapasitas lawan yang dihadapi selama 90 menit permainan berlangsung. Tidak ada kata lain selain kondisi fisik seorang pemain sepakbola harus prima agar tim mampu berprestasi optimal.

Peneliti bertujuan untuk mengetahui kondisi riil bagaimana tingkat kemampuan atau kondisi fisik siswa SSB kelompok usia remaja elit dan non-elit Se-Provinsi Daerah Istimewa Yogyakarta. Adapun komponen kondisi fisik yang akan di teliti adalah indeks massa tubuh, fleksibilitas, power tungkai, kecepatan, koordinasi, kelincahan dan daya tahan aerobik. Kondisi fisik menjadi dasar bagi peneliti untuk tetap dipantau dan diperhatikan sehingga mampu memberikan kontribusi untuk memecahkan masalah-masalah pelatihan dalam bidang persepakbolaan terutama untuk pengembangan kemampuan fisik para pemain sepakbola usia muda yang masih diprediksi memprihatinkan.

\section{METODE}

Penelitian ini adalah penelitian deskriptif kuantitatif, yaitu untuk mengetahui bagaimana kualitas kondisi fisik pada pemain sepakbola remaja elit dan non-elit berposisi. Subjek penelitian ini adalah siswa atau atlet sepakbola pada pemain sepakbola remaja elite dan nonelite. Subjek penelitian dipilih menggunakan teknik purposive. Populasi yang peneliti tetapkan adalah pada pemain sepakbola remaja elite dan non-elite pada sekolah sepakbola atau klub sepakbola di wilayah Provinsi DIY. Sampel yang digunakan dalam penelitian ini adalah para siswa SSB dan Klub sepakbola usia muda (14-16 tahun) di Provinsi DIY dan Malaysia. Teknik penetapan sampel dilakukan dengan cara purposive random sampling dengan salah satu pertimbangannnya adalah keterwakilan siswa untuk setiap kabupaten yang ada di Provinsi DIY.

Instrumen penelitian adalah alat yang digunakan dalam melakukan pengukuran, dalam hal tersebut instrumen penelitian berarti alat untuk mengumpulkan data suatu penelitian. Instrumen dalam penelitian ini adalah tes kondisi fisik (Daya Tahan Aerobik menggunakan MFT/Yoyo Intermitendt Test, Daya Ledak menggunakan Vertical Jump Test, Speed menggunakan 30 meter Sprint Test, Kelincahan menggunakan Illinois Test, Kelenturan menggunakan Sit And Reach.

\section{HASIL DAN PEMBAHASAN}

Kondisi fisik pemain sepak bola diamati berdasarkan 7 komponen kondisi fisik meliputi indeks massa tubuh, fleksibilitas, power tungkai, kecepatan, koordinasi, kelincahan dan daya tahan aerobik. Data hasil analisis kondisi fisik pemain elite dan non-elite dapat dijabarkan pada tabel berikut ini: 
MEDIKORA, Vol. 20 No. 1 April 2021 - 78

Ahmad Nasrulloh, Yudik Prasetyo, Sumaryanto, Sulistiyono, Rina Yuniana

Tabel 2. Hasil Analisis Deskriptif Data Kondisi Fisik Pemain Elite dan Non-Elite

\begin{tabular}{lcccccccc}
\hline \multirow{2}{*}{\multicolumn{1}{c}{ Data }} & \multicolumn{4}{c}{ Elite } & \multicolumn{4}{c}{ Non-elite } \\
\cline { 2 - 9 } & Min. & Max. & Mean & Std. Dev & Min. & Max. & Mean & Std. Dev \\
\hline Indeks massa tubuh & 15,40 & 23,70 & 19,53 & 1,89 & 15,50 & 24,80 & 19,78 & 3,06 \\
Fleksibilitas & 28,50 & 42,00 & 34,40 & 3,75 & 26,00 & 35,50 & 31,14 & 2,75 \\
Power Tungkai & 34,00 & 52,00 & 45,52 & 5,05 & 38,00 & 57,00 & 45,28 & 4,88 \\
Kecepatan & 4,43 & 5,54 & 4,84 & 0,29 & 4,08 & 5,90 & 4,95 & 0,42 \\
Koordinasi & 38,00 & 61,00 & 53,04 & 6,27 & 41,00 & 61,00 & 51,20 & 5,20 \\
Kelincahan & 15,56 & 21,04 & 18,68 & 1,24 & 17,16 & 22,80 & 18,99 & 1,44 \\
Daya Tahan Aerobik & 32,10 & 45,60 & 39,85 & 3,78 & 26,80 & 47,40 & 37,97 & 6,26 \\
\hline
\end{tabular}

Tabel 3. Hasil Analisis Data Kondisi Fisik Pemain Elite dan Non Elite

\begin{tabular}{lcc}
\hline \multirow{2}{*}{ Kondisi Fisik } & \multicolumn{2}{c}{ Nilai Rerata } \\
\cline { 2 - 3 } & Elite & Non Elite \\
\hline Indeks massa tubuh & 19,53 & 19,78 \\
Fleksibilitas & 34,40 & 31,14 \\
Power Tungkai & 45,52 & 45,28 \\
Kecepatan & 4,84 & 4,95 \\
Koordinasi & 53,04 & 51,20 \\
Kelincahan & 18,68 & 18,99 \\
Daya Tahan & 39,85 & 37,97 \\
\hline
\end{tabular}

Berdasarkan tabel di atas diketahui kondisi fisik pada komponen indeks massa tubuh menunjukkan pemain non elite mempunyai indeks massa tubuh yang lebih besar yaitu sebesar 19,78 dibandingkan dengan kelompok elite yaitu sebesar 19,53 dengan perbedaan yang tidak terlalu besar. Dilihat dari komponen fleksibilitas, pemain elite mempunyai fleksibilitas yang lebih tinggi yaitu sebesar 34,40 dibandingkan dengan pemain non elite sebesar 31,14. Perbedaan komponen fleksibilitas cukup besar antara pemain elite dan non elite.

Pada komponen power tungkai menunjukkan perbedaan yang tidak terlalu besar yaitu pada pemain elite sebesar 45,52 dan pada pemain non elite 45,28 dimana power tungkai pada pemain elite lebih tinggi dibandingkan pemain non elite dengan perbedaan yang tidak terlalu besar. Komponen kecepatan juga menunjukkan perbedaan yang tidak telalu besar yaitu 4,48 pada pemain elite dan 4,95.

Dilihat dari komponen koordinasi, pemain elite mempunyai koordinasi yang lebih tinggi yaitu sebesar 53,04 dibandingkan dengan pemain non elite sebesar 51,20. Perbedaan komponen koordinasi cukup besar antara pemain elite dan non elite. Pada komponen kelincahan menunjukkan perbedaan yang tidak terlalu besar yaitu pada pemain elite sebesar 18,68 dan pada pemain non elite 18,99 dimana kelincahan pada pemain non elite lebih tinggi dibandingkan pemain elite dengan perbedaan yang tidak terlalu besar.

Komponen daya tahan menunjukkan bahwa pemain elite mempunyai daya tahan yang lebih tinggi yaitu sebesar 39,85 dibandingkan dengan pemain non elite sebesar 37,97. Perbedaan komponen daya tahan cukup besar antara pemain elite dan non elite. Secara lebih jelas perbandingan kondisi fisik pemain elite dan non elite dapat dilihat pada Gambar 3. 
MEDIKORA, Vol. 20 No. 1 April 2021 - 79

Ahmad Nasrulloh, Yudik Prasetyo, Sumaryanto, Sulistiyono, Rina Yuniana

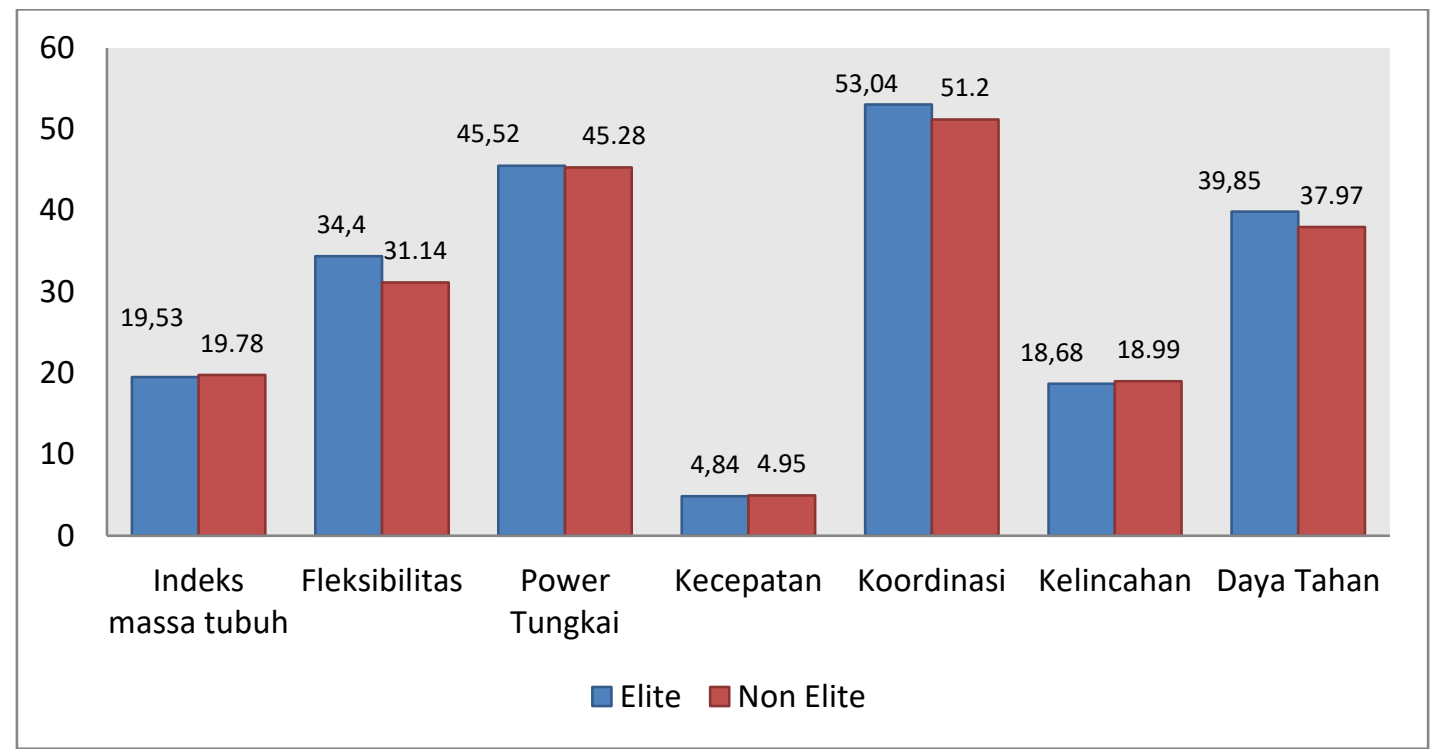

Gambar 3. Kondisi Fisik Pemain Elite dan Non Elite

Berdasarkan diagram di atas menunjukkan perbedaan kondisi fisik pemain elite dan non elite. Hasil analisis menunjukkan bahwa pemain elite dan non elite mempunyai kondisi fisik hampir sama atau berbeda dengan tingkat perbedaan yang cukup kecil.

Kondisi fisik pemain sepak bola diamati berdasarkan 7 komponen kondisi fisik meliputi indeks massa tubuh, fleksibilitas, power tungkai, kecepatan, koordinasi, kelincahan dan daya tahan. Berdasarkan hasil penelitian di atas diketahui kondisi fisik pada komponen indeks massa tubuh menunjukkan pemain non elite mempunyai indeks massa tubuh yang lebih besar yaitu sebesar 19,78 dibandingkan dengan kelompok elite yaitu sebesar 19,53 dengan perbedaan yang tidak terlalu besar. Data indeks massa tubuh menunjukkan pemain non-elite mempunyai indeks massa tubuh yang lebih besar artinya atlit-atlit elite memiliki indeks massa tubuh yang lebih baik dari pada atlit non elite. Indeks massa tubuh sangat mempengaruhi atlet sepkbola dalam bermain sepakbola karena indeks massa tubuh berpengaruh langsung pada penampilan atlet secara keseluruhan (Mahfud et al., 2020). Penelitian terdahulu menjelaskan bahwa atlet elit sepakbola di masa transisi mengalami penambahan berat badan (Mulyawan, 2019). Oleh karena itu diperlukan latihan yang tepat untuk dapat menjaga berat badan tetap ideal untuk dapat menunjang prestasi atlit elit maupun non elit. Salah satu contoh latihan yang dapat dilakukan untuk menjaga agar berat badan tetap ideal adalah dengan latihan body weight training. Seperti dibuktikan dalam sebuah penelitian menyebutkan bahwa latihan beban body weight training menggunkan resistance band lebih efektif dari pada tanpa resistance band terhadap penurunan berat badan dan persentase lemak untuk menjaga berat badan ideal (Lestari \& Nasrulloh, 2019).

Fleksibilitas mengacu pada rentang gerak yang dicapai pada kelompok sendi tanpa menyebabkan cedera (Hoeger \& Hoeger, 2013). Fleksibilitas adalah kemampuan sendi untuk bergerak melalui jangkauan gerak yang tersedia (Baechle \& Earle, 2020). Jadi dapat dikatakan bahwa fleksibilitas merupakan suatu rentang yang dikendalikan oleh kemampuan sendi untuk melakukan gerakan secara maksimal di dalam ruang gerak sendi yang tersedia tanpa menyebabkan cedera. Rentang gerak sendi tersebut adalah merupakan fungsi dari elastisitas tendon, ligamen, dan jaringan lunak di sekitar persendian, sebagai kontrol adalah fungsi kekuatan pada setiap tingkat gerak, terutama pada jangkauan terjauh. Fleksibilitas menunjukkan luasnya pergerakan sendi secara maksimal sesuai dengan kemungkinan gerakan (range of movement). Dilihat dari komponen fleksibilitas, pemain elite mempunyai fleksibilitas yang lebih tinggi yaitu sebesar 34,40 dibandingkan dengan pemain non elite 
sebesar 31,14. Perbedaan komponen fleksibilitas cukup besar antara pemain elite dan non elite, hal ini menunjukkan kemampuan fleksibilitas pemain elit lebih baik dibandingkan pemain non elit. Fleksibilitas ini sangat dibutuhkan oleh setiap pemain sepakbola baik elite maupun non elite agar dapat melakukan gerakdengan luwes dan lebih leluasa pada saat bertanding sepakbola.

Power adalah bahan utama untuk semua cabang olahraga yang membutuhkan kekuatan, kecepatan, dan kelincahan tingkat tinggi(Bompa \& Buzzichelli, 2015) . Dari pendapat tersebut dapat dikatakan bahwa power adalah kemampuan seseorang untuk menghasilkan kecepatan dan kekuatan secara maksimal dalam waktu yang sangat cepat. Hasil penelitian pada komponen power tungkai menunjukkan perbedaan yang tidak terlalu besar yaitu pada pemain elite sebesar 45,52 dan pada pemain non elite 45,28 dimana power tungkai pada pemain elite lebih tinggi dibandingkan pemain non elite dengan perbedaan yang tidak terlalu besar. Pada atlit sepakbola, power ini memiliki peranan penting terhadap performa saat bertanding, oleh karena itu perlu diberikan sebuah latihan yang tepat untuk melatih power pada pemain elite maupun non elite agar power dapat maksimal. Salah satu hasil penelitian mengatakan bahwa untuk latihan power otot tungkai bawah pada atlet sepakbola dapat diberikan terapi dengan latihan alternate leg boud (Rovendra, 2020). Ada juga penelitian yang membuktikan bahwa dengan kinesio tape mempunyai efek yang signifikan terhadap daya ledak otot tungkai (Lesmana \& Nasrulloh, 2020).

Sukadiyanto (2009) mengatakan bahwa kecepatan merupakan kemampuan seseorang untuk menjawab rangsangan dalam bentuk gerak atau serangkaian gerak dalam waktu secepat mungkin. Kecepatan merupakan suatu kemampuan berpindah dari satu tempat ke tempat lain dalam waktu yang sesingkat-singkatnya. Dengan demikian dapat dikatakan bahwa kecepatan adalah kemampuan seseorang untuk menempuh jarak tertentu secara cepat dalam memindahkan tubuh dari satu tempat ke tempat yang lain dalam waktu yang sesingkatsingkatnya. Kecepatan merupakan bagian dari keterampilan motorik kebugaran komponen keterampilan yang diperlukan seseorang untuk beraktivitas dalam kehidupan sehari-hari. Komponen kecepatan juga menunjukkan perbedaan yang tidak telalu besar yaitu 4,48 pada pemain elite dan 4,95 pada non elit. Pada pemain sepakbola, komponen kecepatan ini juga diperlukan pada saat bertanding. Kecepatan juga memiliki korelasi terhadap kemampuan menggiring bola. Terdapat hubungan yang signifikan antara kecepatan dengan kemampuan mendribbling bola pemain sepakbola POPAS FC Kabupaten Pasaman Barat(Saputra \& Yenes, 2019). Oleh karena itu, komponen kecepatan juga perlu diperhatikan dalam proses pelatihan dan pembinaan atlit sepakbola elite maupun non elite.

Koordinasi adalah integrasi sistem saraf dan otot untuk menghasilkan gerakan tubuh yang benar, anggun, dan harmonis (Werner Hoeger, 2010). Artinya dalam melakukan suatu gerakan atau aktivitas seseorang akan terlihat serasi dan harmonis karena antara gerakan dengan rangsang terkoordinasi dengan baik. Makin baik tingkat koordinasi seseorang, makin baik pula tingkat efektivitasnya dalam melakukan aktivitas fisik. Dilihat dari komponen koordinasi, pemain elite mempunyai koordinasi yang lebih tinggi yaitu sebesar 53,04 dibandingkan dengan pemain non elite sebesar 51,20. Perbedaan komponen koordinasi cukup besar antara pemain elite dan non elite membuktikan bahwa pemain elite lebih memiliki kemampuan koordiasi yang baik daripada non elite. Koordinasi merupakan salah satu faktor yang sangat menonjol dalam performa atlit sepak bola. Koordinasi memiliki penranan yang besar pada ketangkasan menendang bola dan koordinasi mata-kaki pemain dalam melakukan teknik gerakan menendang bola dengan baik dan benar. Koordinasi sangat dibutuhkan dalam permainan sepakbola, khususnya dalam melakukan teknik menendang bola agar pemain mampu melakukan tendangan dengan cepat dan tepat sehingga bola terarah (Yulianto \& Pembangunan, 2021). 
Kelincahan adalah merupakan kemampuan untuk mempercepat dan mengurangi kecepatan, cepat mengubah arah dan cepat merubah variasi pola pergerakan, (Bompa \& Buzzichelli, 2015) . Jadi dapat dikatakan bahwa kelincahan adalah kemampuan seorang individu untuk mengubah posisi tubuh secara cepat, baik itu mempercepat maupun memperlambat gerakan secara cepat, tepat dan efektif. Pada komponen kelincahan menunjukkan perbedaan yang tidak terlalu besar yaitu pada pemain elite sebesar 18,68 dan pada pemain non elite 18,99 dimana kelincahan pada pemain non elite lebih tinggi dibandingkan pemain elite dengan perbedaan yang tidak terlalu besar. Pada pemain sepakbola, kelincahan ini memiliki peranan yang signifikan terhadap performa saat bertanding. Kelincahan ini dibutuhkan terutama pada saat melakukan bribling dan menggiring bola. Ada sebuah penelitian yang menemukan bahwa terdapat hubungan yang signifikan antara kelincahan dengan kemampuan mendribbling bola pemain sepakbola POPAS FC Kabupaten Pasaman Barat (Saputra \& Yenes, 2019). Penelitian tersebut memperkuat bahwa komponen kelincahan memiliki peranan penting terhadap performa atlit sepakbola.

Komponen daya tahan aerobik menunjukkan bahwa pemain elite mempunyai daya tahan yang lebih tinggi yaitu sebesar 39,85 dibandingkan dengan pemain non elite sebesar 37,97. Perbedaan komponen daya tahan cukup besar antara pemain elite dan non elite. Hasil penelitian (Ong \& Ong, 2009) dengan pengukuran kondisi daya tahan aerobik pada pemain muda elite pada beberapa negara Asia, Eropa, dan Afrika diperoleh hasil sebesar 60,25. Dari data hasil penelitian yang diperoleh tersebut menunjukkan bahwa data kemampuan daya tahan aerobik atlit elit dan non elit SSB di Daerah Istimewa Yogyakarta menunjukkan hasil yang masih kurang apabila dibandingkan dengan atlit muda di beberapa Negara Asia, Eropa, dan Afrika, meskipun hasil daya tahan aerobik atlit elit menunjukkan rerata yang lebih tinggi dari pada atlit non elit. Oleh karena itu sangat perlu dilakukan latihan lebih intensif untuk dapat meningkatkan daya tahan aerobik mengingat kemampuan daya tahan aerobik ini sangat penting untuk menunjang prestasi sepakbola dan memperbaiki respon kelelahan (Mulyawan, 2020). Salah satu bentuk latihan untuk meningkatkan daya tahan aerobik adalah dengan small side game dan interval training seperti hasil dari sebuah penelitian yang menunjukkan bahwa small side game (SSG) dan interval training (IT) sama efektif dalam meningkatkan daya tahan aerobik pada pemain sepakbola U-17 ( $\mathrm{p}$ < 0.05) (Arianto \& Setyawan, 2019)

\section{SIMPULAN}

Berdasarkan hasil penelitian bahwa menunjukkan bahwa komponen indeks massa tubuh dengan rerata pemain elite sebesar 19,53 dan non elite sebesar 19,78. Fleksibilitas, pemain elite 34,40 dan non elite sebesar 31,14. Power tungkai pemain elite sebesar 45,52 dan pada pemain non elite 45,28. Komponen kecepatan yaitu 4,48 pada pemain elite dan non elite 4,95. Koordinasi, pemain elite sebesar 53,04 dan non elite 51,20. Kelincahan pemain elite sebesar 18,68 dan pada pemain non elite 18,99. Sedangkan daya tahan aerobik pemain elite sebesar 39,85 dan pemain non elite sebesar 37,97. Sehingga dapat disimpulkan bahwa kondisi fisik pemain sepak bola yang meliputi indeks massa tubuh, fleksibilitas, power tungkai, kecepatan, koordinasi, kelincahan dan daya tahan, pemain elite menunjukkan hasil yang lebih baik dibandingkan dengan pemain non-elite. Namun dari seluruh komponen kondisi fisik masih perlu ditingkatkan karena hasil yang diperoleh menunjukkan hasil yang kurang maksimal.

\section{DAFTAR PUSTAKA}

Arianto, A. T., \& Setyawan, C. (2019). Efektivitas small sided games dan interval training terhadap peningkatan daya tahan aerobik pada pemain sepakbola U-17. Jurnal Keolahragaan, 7 (2), 182-191. https://doi.org/10.21831/jk.v7i2.27039

Baechle, T. R., \& Earle, R. W. (2020). Weight Training: Steps to Success. Human Kinetics. 
Bompa, T., \& Buzzichelli, C. (2015). Periodization Training for Sports-3rd Edition. Human Kinetics.

FIFA, Federation International Of Football Association ,2018.

Hoeger, W., \& Hoeger, S. (2013). Principles and Labs for Physical Fitness. Wadsworth, Cengage Learning.

Lesmana, G. I., \& Nasrulloh, A. (2020). The effectiveness of kinesio tape toward the ability of legs muscle's power of amateur basketball players. MEDIKORA 19(2), 61-70. https://doi.org/10.21831/medikora.v19i2.34517

Lestari, A., \& Nasrulloh, A. (2019). Efektivitas Latihan Body Weight Training Dengan Dan Tanpa Menggunakan Resistance Band Terhadap Penurunan Berat Badan Dan Persentase Lemak. MEDIKORA, 17(2), 91-101. https://doi.org/10.21831/medikora.v17i2.29180

Mahfud, I., Gumantan, A., \& Fahrizqi, B.E. (2020). Analisis IMT (Indeks Massa Tubuh) Atlet UKM Sepakbola Univetsitas Teknokrat Indonesia. Ports Athleticism in Teaching and Recreation on Interdisciplinary Analysis, 3, 9-13.

Mulyawan, R. (2019). Profil Antropometri Atlet Sepakbola Profesional Pada Masa Transisi. MEDIKORA, Vol 18, No 1.

Mulyawan, R. (2020). Pengaruh Recovery Aktif Dan Pasif terhadap Daya Tahan Otot. MEDIKORA, Vol. 19 No. 1 April 2020, Hal 53-60.

Ong, D. E. L. P. W., \& Ong, S. T. H. S. W. (2009). Physiological Profile Of Asian Elite Youth Soccer Players. Journal of Strength and Conditioning research (Vol. 23, Issue 5).

PP No. 87 Tahun 2017 Tentang Pengutan Pendidikan Karakter. Jakarta: Kementerian Sekretariat Negara RI.

PP No. 17 Tahun 2010 Tentang Sistem Pendidikan Di Indonesia. Kementerian Pendidikan dan Kebudayaan.

PSSI. 2018. Hasil Sidang Komdis PSSI: 28 Poin Sanksi untuk Klub, Pemain, hingga Suporter. http://wow.tribunnews.com/2018/10/02/hasil-sidang-komdis-pssi-28-poinsanksi-untuk-klub-pemain-hingga-suporter diunduh 28 November 2018Reilly, T., \& Williams, A. M. (2003). Science and Soccer. London: Routledge.

Rovendra, E. (2020). Pengaruh Pemberian Latihan Alternate Leg Bound Untuk Meningkatkan Daya Ledak Otot Tungkai Bawah Pada Atlet Sepak Bola Di Smpn 1 Kota Solok. JHESTECH (Journal Of Health Educational Science And Technology), 3(1), 29. https://doi.org/10.25139/htc.v3i1.2295

Saputra, A., \& Yenes, R. (2019). Hubungan Kelincahan dan Kecepatan terhadap Kemampuan Dribbling Pemain Sekolah Sepakbola. Jurnal Patriot, 1(1), 71-78.

Straton, Gareth, Thomas Reily, A. M. W. and D. R. (2004). Youth Soccer. Routledge. 
MEDIKORA, Vol. 20 No. 1 April 2021 - 83

Ahmad Nasrulloh, Yudik Prasetyo, Sumaryanto, Sulistiyono, Rina Yuniana

Sucipto, (2000). Sepakbola Latihan dan Strategi. Jakarta: Jaya Putra.

Sukadiyanto. (2009). Metode Melatih Fisik Petenis. Fakultas Ilmu Keolahragaan Universitas Negeri Yogyakarta.

Sulistiyono. 2015. Mapping Pengelolaan SSB di Kabupaten Sleman. Proseding Seminar Nasional Keolahragaan.

Werner Hoeger. (2010). Your Complete Solution for Health Personalized Learning Plans. www.cengagebrain.com

Yulianto, R., \& Pembangunan, U. T. (2021). Mata Kaki Pada Pemain Putra Usia 8-10 Tahun Ssb Perseman. 2, 30-37. 